\title{
Effect of Nursing Guideline on Outcomes of Patient With Percutaneous Balloon Valvuloplasty
}

\author{
Al Zahraa Nasr Abd-allah ${ }^{1}$, Mona Aly Mohammed ${ }^{2}$ \&Asmaa Aly Mahgoub ${ }^{3}$. \\ ${ }^{1 .}$ Specialist Nursing at El Dakhla Hospital, New Vally, Egypt. \\ 2. Assistant Professor of Critical care and Emergency Nursing, Faculty of Nursing, Assuit University, Egypt. \\ ${ }^{3 .}$ Assistant Professor of Critical care and Emergency Nursing, Faculty of Nursing, Assuit University, Egypt.
}

\begin{abstract}
Background Many patients with percutaneous balloon valvuloplasty had multiple complications. Thus, they need special nursing guidelines to reduce complications and improve outcomes needed for those patients. Aim of the study To evaluate the effectiveness of nursing guidelines on outcomes of patients with percutaneous balloon valvuloplasty. Research design A randomized control trial was utilized in this study. Settings The study was conducted in the cardiac catheterization unit at Al Orman University Hospital. Sample A convenience sample of 60 patients who were admitted to cardiac catheterization to receive percutaneous balloon valvuloplasty was divided into two equal groups; Intervention and control groups. Tool I patients' assessment sheet, it included four parts; sociodemographic data, patient's assessment measurements, laboratory investigations, and pain scale. Tool II: complications and patient outcome. Methods: the researchers assessed the hemodynamic parameters before and after the procedure. Results more than half $(56.7 \%)$ of the study group had no large hematoma but most of the control group had $<5 \mathrm{~cm}$ of hematoma until discharge of percutaneous balloon valvuloplasty. There was a statistically significant difference between both groups regarding pain, hematoma, and bleeding. Conclusion: Nursing guidelines lead to significant improvement in the outcomes of patients with percutaneous balloon valvuloplasty. Recommendation Keep the nursing guideline of percutaneous balloon valvuloplasty available in the cardiac catheterization unit.
\end{abstract}

\section{Keywords: Nursing guidelines, Outcomes \& Percutaneous balloon valvuloplasty}

\section{Introduction}

When any of the heart valves do not close or open properly, blood flow is affected. When valves do not close completely, blood flows backward through the valve, a condition called regurgitation. When valves do not open completely, a condition called stenosis, the flow of blood through the valve is reduced Disorders of the mitral valve fall into the following categories: mitral valve prolapse (i.e., stretching of the valve leaflet into the atrium during systole), mitral regurgitation and mitral stenosis. Disorders of the aortic valve are categorized as aortic regurgitation and aortic stenosis. These valvular disorders may require surgical repair or replacement of the valve to correct the problem, depending on the severity of the symptom (Khalili et al., 2017).

Stenotic valves are caused by calcific degeneration, congenital abnormalities, or rheumatic heart disease. Calcific aortic and mitral valve degeneration now appears to be the most frequent causes of valve disease requiring surgical treatment or requiring balloon percutaneous valvuloplasty to correct depending on the severity of the symptom (Yadgir et al., 2020).
Percutaneous balloon valvuloplasty (PBV) is a nonsurgical technique for increasing blood flow through stenotic cardiac valves using dilation catheters. This relatively new procedure is similar to percutaneous coronary intervention in that a catheter system is inserted percutaneously and advanced to the region of narrowing using fluoroscopic guidance. A dilation catheter then is inflated to increase the valvular opening and improve blood flow. Balloon valvuloplasty is performed in the cardiac catheterization laboratory. The patient receives light or moderate sedation or just local anesthetic (Mehra et al., 2019).

Balloon valvuloplasty is beneficial for mitral valve stenosis in younger patients, for aortic valve stenosis in elderly patients, and for patients with complex medical conditions that place them at high risk for the complications of more extensive surgical procedures. Most often used for mitral and aortic valve stenosis (Boskovski et al., 2020).

The patient is admitted to the hospital on the day of the PBV procedure. The goal of nursing care is to reduce the cardiac workload, monitor fluid, and electrolyte balance, and reduce psychological stress

Vol, (9) No, (24), March, 2021, pp (140-152) 
so the patient remains hemodynamically stable in most cases, the patient does not have invasive pressure monitoring lines in place before the procedure. The nurse therefore carefully monitors signs and symptoms of heart failure (HF): narrowing in the arterial pulse pressure, more frequent increases in heart rate during activity, peripheral edema, presence of a cough, complaints of dyspnea, or rales in lung fields (Akodad et al., 2019). The nurse also must note any changes in sensory, color, skin temperature, and pulse volume, and any decrease in urinary output. To monitor fluid and electrolyte balance, the nurse obtains a baseline serum electrolyte level and baseline body weight. In addition, daily fluid intake and output are recorded (Pignatelli, 2017).

The patient's medications before admission may have included diuretics, digoxin, and anticoagulants. Before the procedure, any anticoagulant medication is discontinued because of the possibility of emergency surgery (Kochman et al., 2020). The nurse also monitors preliminary laboratory tests and notifies the physician of any abnormalities after the patient fully understands the procedure, the physician must obtain informed consent for PBV anesthesia, and surgery. Surgical standby usually is provided during PBV due to possible complications requiring emergency valve replacement (Andresen, 2018).

\section{Significance of the study:}

Many studies documented that percutaneous valve replacement (PBV) advantages compared with surgery are similar to those of Percutaneous coronary intervention (PCI) versus coronary bypass graft (CABG). PBV is less traumatic, requires no anesthesia, is associated with lower morbidity and a shorter hospital stay, causes no scarring, and is less expensive. Statistics of Egyptian cardiac catheterization unit at Assuit university hospital in the years of (2015 and 2016) revealed that number of patients admitted to the cardiac catheterization unit and planned to percutaneous balloon valvuloplasty were 60 patient (Assuit University Hospital records, 2015 -2016).

\section{Aim of the study:}

The study aimed to evaluate the effectiveness of nursing guidelines on outcomes of patients with percutaneous balloon valvuloplasty.

\section{Hypotheses:}

Percutaneous balloon valvuloplasty complication among patients who receive nursing guidelines (study group) less liable to complication than that among those who receive routine care.

\section{Subjects and Methods}

Research design: Randomized control trial research design was utilized in this study.

Settings: The study was conducted in the cardiac catheterization unit at $\mathrm{Al}$ Orman university hospital.

Sample: A convenience sample of 60 patients who were admitted to cardiac catheterization to receive percutaneous balloon valvuloplasty. The sample was designed controlled group assigned into 2 equal through choosing patient admission numbers (computerized randomization; the singular numbers as an intervention group and paired numbers as a control group). Intervention group: including 30 patients who received routine hospital care in addition to a nursing guideline to evaluate patient complications of this procedure. Control group: including 30 patients who receive routine hospital care only.

Tools of the study:-Two tools were used to collect data for the study after review the local and international scientific journals (Moon \& Angiolillo,2019) \& (Mohammed \& Mohammed, 2016).

Tool 1: patient assessment sheet, this tool includes four parts:

Part 1: patient socio-demographic data as, age, sex, occupation, level of education, and marital status in addition to medical data as the date of admission, medical diagnosis, patient's past health history (previous PVP and diseased valves) presence of any chronic disease. It is used to assess the history of the current disease; past medical diseases; lifestyle, medical diagnosis, and intake and output to assess patient profile.

Part 2: Patients assessment measurements: It included temperature, pulse (peripheral pulse), respiratory rate, blood pressure, and oxygen saturation in addition to monitor ECG rhythm to record hemodynamic data.

Part 3: Laboratory investigations: This part included renal, hepatic, international normalized ratio (INR), and Prothrombin time (PPT), and serum electrolyte to record laboratory investigations.

Part 4: Pain scale: This part aims to help assess a person's pain. The patient usually self-reports their pain using it included rating pain severity from 0 to 10 points while the larger numbers the severity pain interpretations. Zero means "no pain" and 10 mean "the worst possible pain".

Tool II: Complications and patient outcome: This tool consisted of the recorded complications related to the site of insertion and systemic complications. This tool was developed by the researcher to assess the patient outcomes as the occurrence of bleeding, 
aneurysm, heart dysrhythmia, hematomas, etc...through the direct observation of the patient.

Methods:-

Data were collected in three phases:-

1. Preparatory phase for both control, and study groups:-

- Permission to conduct the study was obtained from the hospital responsible authorities in the cardiac catheterization unit $\mathrm{Al}$ Orman university hospital after explaining the aim and nature of the study.

- Tools were developed by the researcher based on the relevant literature reviewing of current and international related literature in various aspects of this study using books and the scientific journal was done.

- The developed tools were tested for clarity and reliability by seven experts in the field of the study and the necessary modifications be done.

- The Reliability was done on the developed tools using Cronbach's Alpha and the reliability level was 0.87 to assess the consistency and stability of the tools.

\section{Pilot study:-}

- A Pilot study was carried out on (6) patients (ten percent (10\%)) of sample to test the clarity of the sheet and estimated the time needed for filling the sheet.

- According to the pilot study, there was no necessary modification was done then the plot sample was added to the main sample.

- The patient was admitted early in the morning at the cardiac catheterization unit.

- Before initiating preoperative teaching the researcher review the patient's characteristics included patient age, sex, etc... besides, medical data by assessing the medical diagnosis and family history (the tool I, part 1 and 2) from the patient hospital folder.

- Then assess the level of understanding and motivation for learning new information and emotional status and apply pre questionnaire sheet in about 10 minutes.

\section{Implementation phases:-}

The researcher introduced herself to the patients and the nursing staff and explained the purpose and nature of the study then recorded and assessed the patient's demographic data from the patient or nurses such as patients, code age, sex, etc...and recorded in tool one part 1.

After patients were recruited to the study, a research nurse has assessed both groups: the control group and the study group.

For the control group (received routine hospital care)
The routine hospital care for the control group when patients were admitted to the cardiac catheterization unit at Assuit university hospital. The nurse attached the patient to the bedside monitor to record the blood pressure, heart rate, perform sample for ABGs.

For the study group: ( received the nursing guideline)

- The researcher assessed the patient and implemented nursing guidelines at admission and for several hours after balloon valvuloplasty by using tools I and II.

- Data were collected in six months approximately from April to October 2019.

- The data were collected from the first day of admission after stabilization of the patient's condition then data recorded in the developed tools.

- Every patient diagnosed with valvular stenosis need to percutaneous balloon valvuloplasty was included in the study.

- All patients (undergoing percutaneous balloon valvuloplasty) admitted in the previously mentioned cardiac catheterization unit were assessed regarding Patient characteristics and clinical data by using the previously mentioned tools.

- The tools were all filled with interviewing patients to explain the purpose of the study and answering the question through 30 minutes for each patient individually.

- The researcher has assessed the patients undergoing percutaneous balloon valvuloplasty using previously mentioned tools from the first day of admission and consequently daily.

- The researchers assess health was clinically diagnosed in patients as Hemodynamic parameters as the level of temperature, pulse, Blood pressure, and respiration, ABGs using (tool II).

- The researchers were done comprehensive baseline neurologic and cardiovascular assessments to identify new neurologic deficits or alterations in cardiovascular status. The researchers should also assess patients for kidney disease, bleeding disorders, and chronic lung disease. The researchers are responsible for providing patient education before the procedure and ensuring all preoperative imaging studies and lab work are completed.

- During the procedure, the researchers monitor patients for hemodynamic during balloon inflation.

- Post-procedure nursing considerations include frequent monitoring for complications, such as neurologic deficits, bleeding, and dysrhythmia. 
Neurovascular assessments of the extremities used for vascular access should also be performed. Patients who have undergone a percutaneous approach are to remain on bed rest. The researchers advance the diet as tolerated. The researchers assessed and documenting fluid status; collecting routine lab specimens, including specimens for complete blood cell count, renal function tests, and a basic metabolic panel and coagulation profile; and reporting any abnormal values. Early mobilization is important to combat potential complications, such as venous thromboembolism. After the bed rest period is completed, the researchers assisted patients to a chair and establish a daily walking regimen. Ensure fall risk assessments have been completed and appropriate interventions are in place to promote patient safety.

- Assess the complications after Percutaneous balloon valvuloplasty (PBV). It consists of the following: Hematoma is defined as swelling around the selected arterial puncture site and will be categorized as being $<5 \mathrm{~cm}$ or $>5 \mathrm{~cm}$ (Berry et al., 2004).

- To measure hematoma two-dimensional ruler with $1 \mathrm{~cm}$ precision was used, the border of hematoma was first determined by palpation technique and then measured by a ruler.

- The bleeding event was defined into three categories; severe bleeding is defined as substantial hemodynamic comprise, moderate bleeding, and minor bleeding as neither requiring transfusion nor resulting in hemodynamic instability for normally distributed (Carson et al., 2016).

- For bleeding, after observing the dressing on the puncture site, the researcher measured the surface area of bleeding on the dressing with this ruler.

- The ischemic limb was assessed by the researcher by palpation of peripheral pulse.

- Assess, duration in the cardiac catheterization unit and length of stay.

- The researchers instruct patients may slowly resume their normal activities. Educated the patient about incision care and signs of infection, signs, and symptoms of fluid overload (such as weight gain), recognizing progressive activity intolerance, and report warning signs such as chest pain or shortness of breath.

Ethical considerations:

- The research proposal was approved by the ethical committee in the Faculty of Nursing; Assiut University. There is no risk for study subjects during the application of the research.
The study followed common ethical principles in clinical research.

- Informed consent was obtained from patients who participated in the study after explaining the nature and purpose of the study or from the responsible person for the unconscious patients. Confidentiality and anonymity were assured.

- Study subjects had the right to refuse to participate or withdraw from the study without any rationale at any time. And Study subjects privacy was considered during the collection of the data

\section{Evaluation phases:}

Evaluation of clinical outcomes for the patient in the control and study groups

- Data for this group was collected from 30 patients who met predetermined criteria in the control group who received routine hospital care using tools I and II. After the implementation phase, a research nurse evaluated the effectiveness of nursing guidelines on outcomes for a patient with percutaneous balloon valvuloplasty.

- The outcomes of using nursing guidelines for intensive patients undergoing percutaneous balloon valvuloplasty after implementing the nursing guidelines using as previously mentioned tool (II)done for both study and control group

\section{Statistical design:}

The collected data were reviewed, prepared for computer entry, coded, categorized, analyzed, and tabulated. Descriptive statistics as mean, standard deviation, number, and percentage, were done using SPSS version 21 Statistically significant difference was considered at $p$-value less than 0.05 ( $p<0.05)$. The t-test was used to determine significant differences for the numeric variables. The chi-square test was used to determine a significant difference in the non-parametric variables. Also, the correlation was done by Pearson Correlation. 


\section{Results}

Table (1):- Distribution of Socio-demographic data related to control and study groups.

\begin{tabular}{|c|c|c|c|c|c|}
\hline \multirow{2}{*}{ Socio-demographic data } & \multicolumn{2}{|c|}{ Control $(n=30)$} & \multicolumn{2}{|c|}{ Study $(n=30)$} & \multirow{2}{*}{ P. value } \\
\hline & No & $\%$ & No & $\%$ & \\
\hline \multicolumn{6}{|l|}{ Age } \\
\hline $20<30$ years & 6 & 20.0 & 7 & 23.3 & \multirow{4}{*}{$0.155 \mathrm{NS}$} \\
\hline $30<40$ years & 14 & 46.7 & 19 & 63.3 & \\
\hline $40-50$ years & 6 & 20.0 & 4 & 13.3 & \\
\hline $50-65$ years & 4 & 13.3 & 0 & 0.0 & \\
\hline \multicolumn{6}{|l|}{ gender } \\
\hline Male & 12 & 40.0 & 14 & 46.7 & \multirow{2}{*}{$0.602 \mathrm{NS}$} \\
\hline Female & 18 & 60.0 & 16 & 53.3 & \\
\hline \multicolumn{6}{|l|}{ Valve disease } \\
\hline Aortic & 12 & 40.0 & 8 & 26.7 & \multirow{2}{*}{$0.411 \mathrm{NS}$} \\
\hline Mitral & 18 & 60.0 & 22 & 73.3 & \\
\hline \multicolumn{6}{|l|}{ Diagnosis } \\
\hline Hypertension & 30 & 100.0 & 30 & 100.0 & - \\
\hline Diabetes Mellites & 16 & 53.3 & 18 & 60.0 & $0.602 \mathrm{NS}$ \\
\hline Previous MI & 14 & 46.7 & 10 & 33.3 & $0.292 \mathrm{NS}$ \\
\hline Previous angina & 8 & 26.7 & 5 & 16.7 & $0.347 \mathrm{NS}$ \\
\hline Previous PBV & - & - & - & - & - \\
\hline Previous CABG & 0 & 0.0 & 1 & 3.3 & $0.313 \mathrm{NS}$ \\
\hline
\end{tabular}

Table (2):- Comparison between Study and control group related to hemodynamic measurement

\begin{tabular}{|c|c|c|c|}
\hline \multirow{2}{*}{ Hemodynamic measurement } & Control & Study & \multirow[b]{2}{*}{ P.value } \\
\hline & Mean \pm SD & Mean \pm SD & \\
\hline \multicolumn{4}{|l|}{ Temperature } \\
\hline Before & $36.96 \pm 0.42$ & $37.14 \pm 0.34$ & 0.072 \\
\hline Immediately after & $36.66 \pm 0.41$ & $37.12 \pm 0.38$ & $<0.001 *$ \\
\hline $30 \min$ & $36.98 \pm 0.16$ & $37.13 \pm 0.24$ & $0.007 *$ \\
\hline $60 \mathrm{~min}$ & $37.17 \pm 0.35$ & $37.31 \pm 0.27$ & 0.084 \\
\hline After next Shift & $37.46 \pm 1.35$ & $37.32 \pm 0.21$ & 0.596 \\
\hline \multicolumn{4}{|l|}{ Respiratory rate } \\
\hline Before & $20.88 \pm 4.09$ & $19.53 \pm 1.83$ & 0.105 \\
\hline Immediately after & $17.07 \pm 2.65$ & $17.73 \pm 1.34$ & 0.224 \\
\hline $30 \min$ & $15.67 \pm 1.69$ & $17.33 \pm 1.67$ & $<0.001 * *$ \\
\hline $60 \mathrm{~min}$ & $16.23 \pm 2.34$ & $15.1 \pm 1.83$ & $0.041 *$ \\
\hline After next Shift & $17.03 \pm 2.17$ & $14.5 \pm 0.97$ & $<0.001 * *$ \\
\hline \multicolumn{4}{|l|}{ Peripheral Pulse } \\
\hline Before & $98.80 \pm 7.90$ & $94.5 \pm 10.57$ & 0.056 \\
\hline Immediately after & $91.1 \pm 17.13$ & $90.17 \pm 9.78$ & 0.796 \\
\hline $30 \mathrm{~min}$ & $89.2 \pm 12.47$ & $87.67 \pm 7.4$ & 0.565 \\
\hline $60 \mathrm{~min}$ & $92.13 \pm 10.65$ & $84.27 \pm 15.3$ & $0.024 *$ \\
\hline After next Shift & $91.63 \pm 26.89$ & $86.17 \pm 4.86$ & 0.278 \\
\hline \multicolumn{4}{|l|}{ SBB } \\
\hline Before & $137.87 \pm 15.15$ & $137.67 \pm 24.02$ & 0.969 \\
\hline Immediately after & $129.03 \pm 28.41$ & $144.17 \pm 18.57$ & $0.018^{*}$ \\
\hline
\end{tabular}




\begin{tabular}{|l|c|c|c|}
\hline \multirow{2}{*}{ Hemodynamic measurement } & Control & Study & \multirow{2}{*}{ P .value } \\
\cline { 2 - 3 } & Mean \pm SD & Mean \pm SD & 0.190 \\
\hline 30 min & $130.5 \pm 23.54$ & $137.87 \pm 19.33$ & 0.229 \\
\hline 60 min & $124.86 \pm 18.14$ & $129.9 \pm 13.41$ & 0.161 \\
\hline After next Shift & $125 \pm 13.83$ & $129.67 \pm 11.52$ & \\
\hline DBB & & & 0.069 \\
\hline Before & $96.67 \pm 10.61$ & $90.33 \pm 15.42$ & 0.087 \\
\hline Immediately after & $89 \pm 17.14$ & $83 \pm 7.94$ & $0.035^{*}$ \\
\hline 30 min & $84 \pm 7.81$ & $80 \pm 6.43$ & 0.685 \\
\hline 60 min & $76.17 \pm 12.23$ & $77.17 \pm 5.52$ & 0.916 \\
\hline After next Shift & $75.33 \pm 6.81$ & $75.5 \pm 5.31$ & \\
\hline Oxygen Saturation & & & 0.122 \\
\hline Before & $91.37 \pm 2.17$ & $92.32 \pm 2.45$ & 0.364 \\
\hline Immediately after & $93.73 \pm 3.88$ & $94.57 \pm 3$ & 0.296 \\
\hline 30 min & $95.13 \pm 2.97$ & $94.29 \pm 3.15$ & $0.037 *$ \\
\hline 60 min & $94.43 \pm 3.08$ & $92.68 \pm 3.19$ & 0.549 \\
\hline After next Shift & $94.47 \pm 4.3$ & $93.89 \pm 2.73$ & \\
\hline
\end{tabular}

Independent samples T-Test $*$ Significant difference at $p$. value $<0.05$

Table (3):- Comparison between Study and control group related to Intake and Output Assessment sheet

\begin{tabular}{|l|c|c|c|}
\hline \multirow{2}{*}{ Intake } & Control & Study & \multirow{2}{*}{ P. value } \\
\cline { 2 - 4 } & Mean \pm SD & Mean \pm SD & \\
\hline Morning & & & 0.221 NS \\
\hline Afternoon & $811.67 \pm 285.17$ & $897 \pm 247.32$ & $0.599 \mathrm{NS}$ \\
\hline Night & $681.67 \pm 360.91$ & $731.67 \pm 370.81$ & 0.384 NS \\
\hline Output & $881.07 \pm 397.53$ & $793.33 \pm 363.82$ & \\
\hline Morning & & & $0.081 \mathrm{NS}$ \\
\hline Afternoon & $578.33 \pm 144.25$ & $651.67 \pm 174.44$ & $0.062 \mathrm{NS}$ \\
\hline Night & $726.67 \pm 243.44$ & $633.33 \pm 112.44$ & $0.080 \mathbf{N S}$ \\
\hline
\end{tabular}

Independent samples T-Test $\quad n *$ Significant difference at $p$. value $<0.05$

Table (4): Relationship between Study and control group related to Complications

\begin{tabular}{|c|c|c|c|c|c|c|c|c|c|c|}
\hline \multirow[b]{3}{*}{ Complications } & \multicolumn{5}{|c|}{ After Procedure } & \multicolumn{5}{|c|}{ Until discharge } \\
\hline & \multicolumn{2}{|c|}{ Control } & \multicolumn{2}{|c|}{ Study } & \multirow{2}{*}{ P. value } & \multicolumn{2}{|c|}{ Control } & \multicolumn{2}{|c|}{ Study } & \multirow{2}{*}{ P. value } \\
\hline & No & $\%$ & No & $\%$ & & No & $\%$ & No & $\%$ & \\
\hline \multicolumn{11}{|l|}{ Pain } \\
\hline Mild & 0 & 0 & 13 & 43.3 & \multirow{3}{*}{$<0.001 * *$} & 20 & 66.7 & 24 & 80 & \multirow{3}{*}{$0.243 \mathbf{~ N S}$} \\
\hline Moderate & 7 & 23.3 & 13 & 43.3 & & 10 & 33.3 & 6 & 20 & \\
\hline Severe & 23 & 76.7 & 4 & 13.3 & & 0 & 0.0 & 0 & 0.0 & \\
\hline \multicolumn{11}{|l|}{ Bleeding } \\
\hline No & 7 & 23.3 & 0 & 0 & \multirow{4}{*}{$0.001 * *$} & 18 & 60 & 0 & 0 & \multirow{4}{*}{$<0.001 * *$} \\
\hline Mild & 7 & 23.3 & 8 & 26.7 & & 11 & 36.7 & 25 & 83.3 & \\
\hline Moderate & 9 & 30 & 21 & 70 & & 1 & 3.3 & 5 & 16.7 & \\
\hline Severe & 7 & 23.3 & 1 & 3.3 & & 0 & 0.0 & 0 & 0.0 & \\
\hline \multicolumn{11}{|l|}{ Hematoma } \\
\hline $\mathrm{No}$ & 7 & 23.3 & 0 & 0 & \multirow{3}{*}{$0.001 * *$} & 17 & 56.7 & 0 & 0 & \multirow{3}{*}{$<0.001 * *$} \\
\hline$>5$ & 22 & 73.3 & 21 & 70 & & 7 & 23.3 & 3 & 10 & \\
\hline$<5$ & 1 & 3.3 & 9 & 30 & & 6 & 20 & 27 & 90 & \\
\hline
\end{tabular}

Chi-squaretest, ${ }^{*}$ Significantdifference at p. value $<0.05$ NS:- Not Significan 
Table (1) showed that there was no statistically significant difference between the study and control groups regarding their demographic characteristics. The table also, revealed that the majority of the studied group ages were $30<40$ years, (46.7 and 63.3 respectively), and female (60 and $53.3 \%$ respectively). Also, they revealed that there was no statistically significant difference between the study and control groups regarding their Clinical data. The table also, revealed that all $(100 \%)$ of both groups suffered from hypertension. In addition, the majority of them had Diabetes mellitus (53.3 and 60\% respectively). Regarding the history around half $(46.7 \%)$ of the control group had previous MI and more than one-third of the study group had previous MI.

Table (2) found that there was a statistically significant difference between the study and control groups regarding body temperature and blood pressure after 15,30 , and 60 minutes of percutaneous balloon valvuloplasty. Regarding oxygen saturation that there was a statistically significant difference between the study and control groups regarding body temperature after 60 minutes of Percutaneous balloon valvuloplasty the study control better than the study group after the next shift with a mean $(94.47 \pm 4$.3and $93.89 \pm 2.73$ respectively) with an improvement after the next shift among the study group $(92.32 \pm 2.45$ and 93.89 \pm 2.73$)$.

Table (3) found that there was no statistically significant difference between the study and control groups regarding intake and output in the deferent times except regarding the output afternoon shift with p. value $(0.034)$

Table (4); found that there was a statistically significant difference between the study and control groups regarding complications of PBV after and until discharge after Percutaneous balloon valvuloplasty except regarding pain level until discharge after PBV. The table also revealed regarding pain, the majority of both groups had no severe pain until discharge. Regarding bleeding, no patient had severe bleeding until discharge among both study and control groups. Regarding hematoma until discharge more than half of the study group had no hematoma but most of the control group (90\%) had $<5 \mathrm{~cm}$ of hematoma until discharge of PBV.

\section{Discussion:}

Patients undergoing percutaneous balloon valvuloplasty should be provided an education and facilitate support. It is important that the patient undergoing Percutaneous Balloon Mitral Valvotomy (PBMV) needs to be assessed to improve both the quality and value of care for them (Boskovski et al.,
2020). Therefore, the present study aimed to evaluate the effectiveness of nursing guidelines on outcomes for patients with percutaneous balloon valvuloplasty. The present study revealed that there was no statistically significant difference between the study and control groups regarding their Clinical data. In addition, it revealed that all patients of both groups suffered from hypertension and diabetes mellitus. Regarding the history; around half of the control group had previous myocardial infarction (MI) and more than one-third of the study group had previous MI.

This matches with Mosch et al., (2017) who concluded that diabetes mellitus (DM) adversely affects morbidity and mortality for major atherosclerosis-related cardiovascular diseases and is associated with increased risk for the development of aortic stenosis. Clinical data regarding the impact of DM on outcomes of patients' undergoing aortic valve replacement (AVR) have revealed inconsistent results. Furthermore, DM is associated with increased risk for the development of AS and was found to be the second most significant factor associated with aortic stenosis (AS) after hypertension (Yan et al., 2017).

Other independent predictors of Percutaneous balloon valvuloplasty (PBV) during the first 30 days were older age, male sex, history of hypertension, obesity, diabetes mellitus, myocardial infarction, history of pulmonary edema, atrial fibrillation, left bundle branch block, right bundle branch block, and abnormal renal function (Tastet et al., 2017).

Williams et al., (2018) addressing the association between arterial hypertension and calcific aortic stenosis (AS) have reported conventional office blood pressure (BP) only, and clinical practice has entirely been based on such measurements, which should be conducted according to current recommendations. Mohammed \& Mohammed, (2016) study shows that $36.7,30.0$ of the study sample and 30.0, 53.3 of the control sample of patients undergoing Percutaneous coronary intervention (PCI) with percutaneous balloon valvuloplasty had hypertension and diabetes mellitus. Tsantes et al., (2019) agreed with the current study reported that $36.7 \%$ of the study had hypertension and $49 \%$ had diabetes mellitus. Also, Sung et al., (2020) stated that cardiac catheterization is more common in people who suffer from medical diagnosis (ischemic heart disease) and coronary heart disease associated with hypertension, diabetes mellitus, and renal diseases.

Regarding current medications, the present study revealed that there was no statistically significant difference between the study and control groups, and all of both groups received anti-hypertension drugs. 
In addition, the majority of them received betablockers. The risk for hypotension is increased in patients with symptomatic, and systolic left ventricle (LV) dysfunction. Also, there is circumstantial evidence that an achieved systolic BP below $120 \mathrm{mmHg}$ or a diastolic BP below $70 \mathrm{mmHg}$ in high-risk cardiovascular patients (including diabetes and coronary artery disease) is associated with an increased risk for adverse cardiovascular events (Nielsen et al., 2016).

Thus, Vidal-Petiot et al., (2016) added that, although antihypertensive treatment in AS patients, in general, should follow the guideline recommendations for the management of arterial hypertension, care should be taken to avoid hypotension. Furthermore, in patients with severe AS, symptomatic AS, or known heart failure or LV systolic dysfunction, antihypertensive treatment should follow expert evaluation at Heart Valve Clinics in the individual patient.

In this respect, Nijenhuis et al., (2016) mentioned that Antiplatelet agents have given prior and after balloon valvuloplasty with percutaneous balloon valvuloplasty: Aspirin (200 mg) and clopidogrel (300 $\mathrm{mg}$ ) were administered at least $6 \mathrm{~h}$ before the procedures. The current study documented that all patients administered antiplatelet pre and post percutaneous balloon valvuloplasty. This is in the same line with Moon \&Angiolillo, (2019), which demonstrated that aspirin and other Antiplatelet drugs were indicated indefinitely.

Nurses administering these medications should be familiar with the drug action, correct dosing, and potential side effects. Verbal and written communication to other team members regarding the type, dose, time, and patient reaction can be instrumental in preventing errors that can lead to vascular complications. Davidson et al., (2019) mentioned that antiplatelet agents include aspirin and other Antiplatelet agents, such as ticlopidine hydrochloride (Ticlid), clopidogrel (Plavix), eptifibatide (Integrilin), tirofiban hydrochloride (Aggrastat), or abciximab (ReoPro) do not need to be stopped before balloon valvuloplasty These Antiplatelet agents reduce the frequency of ischemic complications after balloon valvuloplasty.

Kapadia et al., (2017) mentioned that it is important to note that the use of Antiplatelet agents such as acetylsalicylic acid (aspirin) and thienopiridynes (ticlopidin, clopidogrel, or prasugrel) as adjunctive therapy for patients submitted to balloon valvuloplasty is mandatory because these medications prevent thrombus formation in the coronary arteries. Kumar et al., (2016) documented that, it is difficult to estimate their influence on the bleeding risk after balloon valvuloplasty.
At the same time, the researchers' opinion that these medications prevent ischemic events caused by thrombus formation, their effect could influence platelet aggregation and thrombus formation at the puncture site in the femoral artery, leading to an increase in the femoral bleeding risk, even so, most of the patients did not present bleeding events after the procedure while using Antiplatelet agents.

Regarding the hemodynamic measurement; the existing study found that there was a statistically significant difference between the study and control groups regarding body temperature after 15, 30, and 60 minutes of Percutaneous balloon valvuloplasty. The results also, revealed there was a statistically significant difference between the study and control groups regarding respiratory rate after 30 minutes and after the next shift of Percutaneous balloon valvuloplasty. In addition, there was a statistically significant difference between the study and control groups regarding peripheral pulse after 60 minutes of the percutaneous balloon valvuloplasty. Regarding systolic blood pressure that there was a statistically significant difference between the study and control groups regarding body temperature after 15, and 30 minutes of Percutaneous balloon valvuloplasty.

In addressing the development of hypertension within the first five days after valve replacement, other investigators have reported a significant increase in systolic blood pressure by $(15 \pm 31 \mathrm{mmHg})$ in a cohort of 105 patients following successful PBV; this rise in blood pressure was sustained and led to an intensification of antihypertensive treatment in 53 of these patients, was associated with an increase in $\mathrm{CO}$, and predicted a better clinical outcome (Carabello, 2020).

In the Plessis et al., (2018) study, a trend was observed towards an increase in systemic arterial pressure much earlier in the entire patient cohort; in the initial $6 \mathrm{hrs}$. the systolic blood pressure was increased by $3.2 \pm 26.1 \mathrm{mmHg}(\mathrm{p}=0.06)$, and at $24 \mathrm{~h}$ by $6.7 \pm 29.6 \mathrm{mmHg}(\mathrm{p}=0.04)$. These changes appeared significant enough to necessitate the use of low doses of intravenous nitrates in $56.5 \%$ of patients as a short-term, easy-to-titrate, antihypertensive agent in the ICU (Chrissoheris et al., 2016).

Similarly, the Vieillard-Baron et al., (2018) study showed a statistically significant decline in diastolic blood pressure at $6 \mathrm{~h}$ by $5.2 \pm 11.6 \mathrm{mmHg}$ and at $24 \mathrm{~h}$ by $5.6 \pm 13.4 \mathrm{mmHg}$. A potential explanation for this may be significant coexisting residual paravalvular aortic regurgitation; in the present study, however, it was observed that after PBV fewer patients appeared to have AR grades $\geq 2$ compared to before the procedure $(24 \%$ versus $46.6 \%)$; overall, the comparison of AR grades between baseline and after 
Transcatheter valve replacement (TAVR) failed to show any statistical significance $(\mathrm{p}=0.14)$.

Thus, the decline in diastolic blood pressures more likely reflects the significant reduction in systemic vascular resistance (up to $35.3 \%$ for the entire cohort) that was observed following percutaneous balloon valvuloplasty (PBV) (Praz et al., 2018).

Other studies have shown that some patients have gradual mitral valve restenosis is lower than that preoperatively during long-term follow-up. However, cardiac functions in some patients are still normal, and they can engage in heavier physical activity with less influence. In our study, after successful primary percutaneous balloon mitral valvuloplasty (PBMV), recurrent restenosis was detected in 35 patients, but 9 of them $(25.7 \%)$ did not have significant clinical symptoms and have a normal cardiac function; thus, repeat percutaneous balloon mitral valvuloplasty (PBMV) was not performed (Mahfouz et al., 2017).

The main reason may be that cardiac function is affected by integrated factors postoperatively. Mitral reserve function is the main factor in determining cardiac output increase in equal load status. According to the physiological needs, an increase in mitral valve area (MVA) presents the mitral reserve function (Zhang et al., 2019).

Generally, a normal person's mitral valve reserve rate is $30 \%$ to $50 \%$. Therefore, compared with mitral valve area (MVA) in the resting state postoperatively, mitral valve reserve function is valuable in the estimation of cardiac function (Walsh, 2019).

Regarding diastolic blood pressure that there was a statistically significant difference between the study and control groups regarding body temperature after 30 minutes and one hour of percutaneous balloon valvuloplasty. Regarding oxygen saturation that there was a statistically significant difference between the study and control groups regarding body temperature after 60 minutes of Percutaneous balloon valvuloplasty the study control better than the study group after the next shift with a mean $(94.47 \pm 4.3$ and $93.89 \pm 2.73$ respectively) with an improvement after the next shift among the study group $(92.32 \pm 2.45$ and 93.89 \pm 2.73 ).

The National Heart Lung and Blood Institute (NHLBI) balloon valvuloplasty registry collected data on patients undergoing BAV in the USA and Canada between 1987 and 1989 and forms the most comprehensive early outcome data set.18 In 1991 the group published a 30-day follow-up on a cohort of 674 patients. Haemodynamically post bicuspid aortic valve (BAV), aortic valve area increased from 0.5 to $0.8 \mathrm{~cm} 2$ with a concomitant decrease in peak aortic gradient from 65 to $31 \mathrm{~mm} \mathrm{Hg}$ associated with a small but significant increase in cardiac output.
Similar results were reported from the Mansfield Scientific Aortic Valvuloplasty Registry of 492 patients between 1986 and 1987 where an increase in aortic valve area from 0.5 to $0.8 \mathrm{~cm} 2$, a decrease in peak aortic gradient from 60 to $30 \mathrm{~mm} \mathrm{Hg}$, and an increase in cardiac output from 3.86 to $4.05 \mathrm{~L} / \mathrm{min}$ was observed (Keeble et al., 2016).

The Mansfield registry assessed the impact of procedure-related variables on acute valvuloplasty and post valvuloplasty hemodynamic changes. The only variable associated with a significant difference was balloon inflation time whereby an inflation time between 30 and $60 \mathrm{~s}$ resulted in a larger final aortic valve area, but no difference in aortic valve gradient when compared with inflation times of $<30$. They concluded that short inflation times $(<30)$ should be avoided. The size of the largest balloon used, the number of balloons, the number of balloon exchanges, and the use of single or double balloons made no significant difference to post-procedure hemodynamic (Piayda et al., 2018).

Furthermore, Trans-catheter valve replacement (TAVR) in the beating heart affords a clear understanding of the immediate hemodynamic responses to abrupt removal of the impediment to left ventricular outflow (Nguyen, 2014). The abovedescribed hemodynamic changes have several clinical implications. Patients often require loading with intravenous fluids to maintain an adequate preload. In addition, there is an occasional adequate afterload, especially when the left ventricle is significantly hypertrophied and hyperdynamic.

The development of significant systolic hypertension post-procedure should also be anticipated, as shown by others, and may require the adjustment of antihypertensive treatments. A decline in diastolic arterial pressures may also be anticipated, and barring significant coexistent paravalvular aortic regurgitation this likely is due to a substantial decline in systemic vascular resistances seen during the acute phase (Berridge et al., 2016).

The existing study found that there was no statistically significant difference between the study and control groups regarding intake and output in the different times except regarding the output afternoon shift with a p. value (0.034). Whilst, Filippetti, et al., (2018) demonstrated a significant reduction in circulation flow rate in patients with MS, with a significant increase in circulation flow after percutaneous balloon mitral valvuloplasty (PBMV).

The present study found that there was a statistically significant difference between the study and control groups regarding complications of PBV after and until discharge after Percutaneous balloon valvuloplasty except regarding pain level until 
discharge after PBV. This study also revealed regarding pain, the majority of both groups had no severe pain until discharge.

Regarding bleeding; the was no patient had severe bleeding until discharge among both study and control groups and more than half of the study group had no hematoma but most of the control group $(90 \%)$ had $<5 \mathrm{~cm}$ of hematoma until discharge of PBV. Otto et al., (2017) performed that a goal following percutaneous balloon valvuloplasty is to reduce vascular complications, especially hematoma formation, the most common access site complication.

However, Seto et al., (2018)stated that the incidence of vascular access complications alone has ranged from $0.1 \%$ to $61 \%$, depending on the definition of complications, the type of procedure, anticoagulation, closure devices, age, sex, and other patient comorbidities. Shin et al., (2018) added vascular complications expose patients to additional discomfort, extended hospital stay, and higher hospital costs. Also, Egholm et al., (2016) reported that the incidence of perioperative complications with non-cardiac surgery post-second-generation DES implantation was $11 \%$ and consisted mainly of bleeding $(5.8 \%)$ and the incidence of thrombosis was $0.7 \%$.

Lip et al., (2019) reported relatively low rates of mortality, myocardial infarction, or repeat revascularization $(5.4 \%)$ at 48 hours. Similarly, Leng et al., (2019) reported an overall rate of $3.3 \%$ for death, myocardial infarction, and urgent revascularization with 2,500 IU of heparin before balloon valvuloplasty. Also, Gori et al., (2019) reported that the most common and consistent predictors of post percutaneous balloon valvuloplasty thrombosis are early Antiplatelet therapy discontinuation and the extent of coronary disease.

\section{Conclusion:}

Based on the results of this study, it could be concluded that nursing guidelines lead to significant improvements in patients outcomes of percutaneous balloon valvuloplasty patients and reduce insertion site complications as a hematoma.

\section{Recommendations:}

Based on the findings of the study, the following recommendations have been made.

1.Keep the nursing guideline of percutaneous balloon valvuloplasty available in the cardiac catheterization unit.

2.Reapplication of the study on a large probability of sample from different geographical is required.
3.Studying the risk factors associated with a complication for the patient after percutaneous balloon valvuloplasty.

\section{References}

- Akodad, M., Schurtz, G., Adda, J., Leclercq, F., \& Roubille, F. (2019): Management of valvulopathies with acute severe heart failure and cardiogenic shock. Archives of cardiovascular diseases, 112(12), P.P. 773-780

- Andresen, B. (2018). Percutaneous pulmonary valve implantation impact on clinical outcome, patients self-reported health, psychosocial function, and hospital costs in patients with congenital heart disease, P. 589.

- Assuit University Hospital records, 2015 -2016

- Berridge, B. R., Mowat, V., Nagai, H., Nyska, A., Okazaki, Y., CleMents, P. J., \& Wells, M. Y. (2016). Non-proliferative and proliferative lesions of the cardiovascular system of the rat and mouse. Journal of toxicological pathology, 29(3), P.P. 1S-47S.

- Berry, C., Kelly, J., Cobbe, S. M., \& Eteiba, H. (2004). Comparison of femoral bleeding complications after coronary angiography versus percutaneous coronary intervention. The American journal of cardiology, 94(3), P.P. 361-363.

- Boskovski, M. T., Nguyen, T. C., McCabe, J. M., \& Kaneko, T. (2020). Outcomes of transcatheter aortic valve replacement in patients with severe aortic stenosis: a review of disruptive technology in aortic valve surgery. JAMA Surgery, 155(1), P.P. 69-77

- Carabello, B. A. (2020). Evidenced-Based and Practical Management of Real-World Valvular Heart Disease. In Valvular Heart Disease, Springer, London, P.P. 285-305.

- Carson, J. L., Stanworth, S. J., Roubinian, N., Fergusson, D. A., Triulzi, D., Doree, C., \& Hebert, P. C. (2016). Transfusion thresholds and other strategies for guiding allogeneic red blood cell transfusion. Cochrane database of systematic reviews, (10) P.P.87-90.

- Chrissoheris, M., Ziakas, A., Chalapas, A., Chadjimiltiades, S., Styliades, I., Karvounis, C., and Spargias, K. (2016). Acute invasive hemodynamic effects of transcatheter aortic valve replacement. J Heart Valve Dis, 25(2), P.P. 162-172.

- Davidson, J. C. Jon C. Davidson, MD, Shiraz Rahim, MD, Sue E. Hanks, MD, Indravadan J. Patel, MD, Alda L. Tam, MD, T. Gregory Walker, MD, Ido Weinberg, MD, Luke R. Wilkins, MD, \&Ravi Sarode, MD. J (2019). 
Endorsed by the Canadian Association for Interventional Radiology and the Cardiovascular and Interventional Radiological Society of Europe Vasc Interv Radiol, 30, P.P. 1155-1167.

- Egholm, G., Thim, T., Olesen, K. K., Madsen, M., Sorensen, H. T., Jensen, S. E.,... \& Maeng, M. (2016). Dual antiplatelet therapy after coronary drug-eluting stent implantation and surgery-associated major adverse events. Thrombosis and Haemostasis, 116(07), P.P. 172-180.

- Filippetti, L., Voilliot, D., Bellino, M., Citro, R., Go, Y. Y., and Lancellotti, P. (2018). The right heart-pulmonary circulation unit and left heart valve disease. Heart failure clinics, 14(3), P.P. 431-442.

- Gori, T., Polimeni, A., Indolfi, C., Räber, L., Adriaenssens, T., \& Münzel, T. (2019). Predictors of stent thrombosis and their implications for clinical practice. Nature Reviews Cardiology, 16(4), P.P. 243-256.

- Kapadia, S., Chew, D., Cura, F., L'Allier, P. L., Roffi, M., and Tuzcu, E. M. (2017). Textbook of Interventional Cardiology: Global Perspective. JP Medical Ltd., P.P. 56-58

- Keeble, T. R., Khokhar, A., Akhtar, M. M., Mathur, A., Weerackody, R., \& Kennon, S. (2016). Percutaneous balloon aortic valvuloplasty in the era of transcatheter aortic valve implantation: a narrative review. Open Heart, 3(2), P.P.78.

- Khalili, F., Gamage, P., \& Mansy, H. A. (2017). Hemodynamics of a bileaflet mechanical heart valve with different levels of dysfunction. arXiv preprint arXiv, P.P. 1711.11153

- Kochman, J., Zbroński, K., Koltowski, L., Parma, R., Ochała, A., Huczek, Z., \& Scisło, P. (2020). Transcatheter aortic valve implantation in patients with bicuspid aortic valve stenosis utilizing the next-generation fully retrievable and repositionable valve system: mid-term results from a prospective multicentre registry. Clinical Research in Cardiology, 109(5), P.P. 570-580

- Kumar, A., Paniagua, D., Hira, R. S., Alam, M., Denktas, A. E., \& Jneid, H. (2016). Balloon aortic valvuloplasty in the transcatheter aortic valve replacement era. J Invasive Cardiol, 28(8), P.P. 341-348.

- Leng, W., Yang, J., Fan, X., Sun, Y., Xu, H., Gao, X., ... and Jia, S. (2019). Contemporary invasive management and in-hospital outcomes of patients with non-ST-segment elevation myocardial infarction in China: findings from
China Acute Myocardial Infarction (CAMI) Registry. American heart journal, 215, P.P. 111.

- Lip, G. Y., Collet, J. P., Haude, M., Byrne, R., Chung, E. H., Fauchier, L., \& Marin, F. (2019). European consensus document on the management of antithrombotic therapy in atrial fibrillation patients presenting with the acute coronary syndrome and/or undergoing percutaneous cardiovascular interventions, European Association of Acute Cardiac Care (ACCA) endorsed by the Heart .... Ep Europace, 21(2), P.P. 192-193.

- Mahfouz RA, Elawady W, Goda M, (2017). Redo scoring for prediction of success of redo-percutaneous balloon mitral valvuloplasty in patients with mitral restenosis. J Heart Valve Dis;26, P.P. 537-46.

- Mehra, A., Muadi, G., Reddy, P., \& Elkayam, U. (2019). Catheter-Based Interventions in Women with Heart Disease During Pregnancy. Cardiac Problems in Pregnancy, P.P. 370-388

- Mohammed, G. T., \& Mohammed, Z. A. (2016). Impact of designed nursing educational protocol on health promotion for patients undergoing coronary artery stent outcome. Assiut Scientific Nursing Journal, 4(7), P.P. 36-45.

- Moon, J. Y., \& Angiolillo, D. J. (2019). Antiplatelet Drugs in the Management of Coronary Artery Disease. In Platelets. Academic Press. P.P. 1017-1029.

- Mosch J, Gleissner CA, Body S, Aikawa E. (2017). Histopathological assessment of calcification and inflammation of calcific aortic valves from patients with and without diabetes mellitus. Histol Histopathol.32, P.P. 293-306

- Nguyen, B. A. V. (2014). Characterization and modulation of the intracellular inflammatory signalling pathways activated during surgery with cardiopulmonary bypass, P.P. 125-145.

- Nielsen, O. W., Sajadieh, A., Sabbah, M., Greve, A. M., Olsen, M. H., Boman, K., ... \& Wachtell, K. (2016). Assessing optimal blood pressure in patients with asymptomatic aortic valve stenosis: The Simvastatin Ezetimibe in Aortic Stenosis Study (SEAS). Circulation, 134(6), P.P. 455-468.

- Nijenhuis, V. J., Bennaghmouch, N., Hassell, M., Baan Jr, J., Van Kuijk, J. P., Agostoni, P., \& Van Den Heuvel, A. F. (2016). Rationale and design of POPular-TAVI: antiplatelet therapy for patients undergoing transcatheter 
aortic valve implantation. American heart journal, 173, P.P. 77-85.

- Otto, C. M., Kumbhani, D. J., Alexander, K. P., Calhoon, J. H., Desai, M. Y., Kaul, S., and Vassileva, C. M. (2017). An expert consensus decision pathway for transcatheter aortic valve replacement in the management of adults with aortic stenosis: a report of the American College of Cardiology Task Force on Clinical Expert Consensus Documents. Journal of the American College of Cardiology, 69(10), P.P. 1313-1346.

- Piayda, K., Wimmer, A. C., Veulemans, V., Afzal, S., Sievert, H., Gafoor, S., \&Westenfeld, R. (2018). Balloon valvuloplasty followed by transcatheter aortic valve implantation as a staged procedure in patients with low-flow low-gradient aortic stenosis. J Invasive Cardiol, 30(12), P.P. 437-442.

- Pignatelli, N. P. L. M. (2017). Design of a mobile kit for cardiovascular disease screening in resource-constrained environments (Doctoral dissertation, Massachusetts Institute of Technology), P.P. 37-44.

- Plessis, J., Hascoët, S., Baruteau, A., Godart, F., Le Gloan, L., Fresse, K. W., and Guérin, P. (2018). Edwards SAPIEN transcatheter pulmonary valve implantation: results from a French registry. JACC: Cardiovascular Interventions, 11(19), P.P.1909-1916.

- Praz, F., Khalique, O. K., Lee, R., Veeragandham, R., Russell, H., Guerrero, M., and Leon, M. B. (2018). Transarterial implantation of a transcatheter heart valve for severe mitral annular calcification. The Journal of Thoracic and Cardiovascular Surgery, 156(1), P.P. 132-142

- Seto, A. H., Shroff, A., Abu-Fadel, M., Blankenship, J. C., Boudoulas, K. D., Cigarroa, J. E., and Swaminathan, R. V. (2018). Length of stay following percutaneous coronary intervention: an expert consensus document update from the society for cardiovascular angiography and interventions. Catheterization and Cardiovascular Interventions, 92(4), P.P. 717731.

- Shin, C. H., Long, D. R., McLean, D., Grabitz, S. D., Ladha, K., Timm, F. P., and Scheeren, T. W. (2018). Effects of intraoperative fluid management on postoperative outcomes: a hospital registr study. Annals of Surgery, 267(6), P.P.1084-1092.

- Sung, P. H., Li, Y. C., Lee, M. S., Hsiao, H. Y., Ma, M. C., Pei, S. N., ... and Yip, H. K. (2020). Intracoronary Injection of Autologous
CD34+ Cells Improves One-Year Left Ventricular Systolic Function in Patients with Diffuse Coronary Artery Disease and Preserved Cardiac Performance-A Randomized, OpenLabel, Controlled Phase II Clinical Trial. Journal of clinical medicine, 9(4), P.1043.

- Tastet, L., Capoulade, R., Clavel, M. A., Larose, É., Shen, M., Dahou, A., and Tremblay, A. (2017). Systolic hypertension and progression of aortic valve calcification in patients with aortic stenosis: results from the PROGRESS study. European Heart JournalCardiovascular Imaging, 18(1), P.P. 70-78.

- Tsantes, A. E., Taichert, M., Kyriakou, E., Katogiannis, K., Lytras, T., Gialeraki, A., and Poulis, A. (2019). The prognostic value of multiple electrode aggregometry and light transmittance aggregometry in stable cardiovascular patients with type 2 diabetes mellitus. Thrombosis research, 180, P.P. 47-54.

- Vidal-Petiot, E., Ford, I., Greenlaw, N., Ferrari, R., Fox, K. M., Tardif, J. C., \&CLARIFY investigators. (2016). Cardiovascular event rates and mortality according to achieved systolic and diastolic blood pressure in patients with stable coronary artery disease: an international cohort study. The Lancet, 388(10056), PP..2142-2152.

- Vieillard-Baron, A., Naeije, R., Haddad, F., Bogaard, H. J., Bull, T. M., Fletcher, N., \&Pinsky, M. R. (2018). Diagnostic workup, etiologies, and management of acute right ventricle failure. Intensive care medicine, 44(6), P.P. 774-790.

- Walsh, M. T. (2019). Ambulatory Anesthesia, An Issue of Anesthesiology Clinics, Elsevier Health Sciences, E-Book,37( 2), P. 67.

- Williams, B., Mancia, G., Spiering, W., Agabiti Rosei, E., Azizi, M., Burnier, M., \&Kahan, T. (2018). Guidelines for the management of arterial hypertension: The Task Force for the management of arterial hypertension of the European Society of Cardiology (ESC) and the European Society of Hypertension (ESH). European heart journal, 39(33), P.P.3021-3104.

- Yadgir, S., Johnson, C. O., Aboyans, V., Adebayo, O. M., Adedoyin, R. A., Afarideh, M., \& Azari, S. (2020). Global, Regional, and National Burden of Calcific Aortic Valve and Degenerative Mitral Valve Diseases, 19902017. Circulation, 141(21), P.P.1670-1680.

- Yan AT, Koh M, Chan KK, Guo H, Alter DA, Austin PC, (2017). Association between cardiovascular risk factors and aortic stenosis: 
the CAN HEART Aortic Stenosis Study. J Am Coll Cardiol,69:P.P. 1523-32

- Zhang, L., Hou, J., Duan, Y., Chen, J., Du, H., \& Shi, Z. (2019). Study on the long-term curative effect of repeat percutaneous balloon mitral valvuloplasty in patients with mitral restenosis. Medicine, 98(32), P. 45. 